\title{
L'Aviculture au Maroc
}

\author{
par G. HENRY
}

L'AVICULTURE, pratiquée empiriquement au Maroc depuis environ dix siecles avant notre ère, tient depuis longtemps une place indiscutable dans l'économie du pays.

Le commerce des œufs et des volailles y a toujours été actif, sur les souks ruraux comme dans les médinas et dans les ports d'exportation.

Dès 1890, deux vapeurs anglais venaient tous les mois à Mazagan charger les œufs des Doukkala, bientôt suivis par des voiliers espagnols venus de Cadix et de Malaga. A partir de 1905, le marché français s'ouvre à son tour aux cufs marocains.

La production pour l'exportation connaît des hauts et des bas, selon les circonstances, sans jamais s'interrompre totalement, comme le montre le tableau joint où les sorties d'œufs sont notées en tonnes (Tableau I).

Depuis juin 1932, un arrêté viziriel autorise l'exportation des volailles, jusque-là interdite.

Presque aussitôt, un nouveau commerce s'organise et prospère, jusqu'à la dernière guerre, ainsi qu'en témoignent les chiffres ci-après (Tableau II).

Ce trafic d'œufs et de volailles, intéressant -déjà sur le plan économique, mérite au surplus de retenir l'attention du point de vue social. La volaille est en effet, au Maroc, la propriété de la femme. C'est avec l'argent qu'elle retire de la vente des ceufs et des poulets que la marocaine peut, sur le souk, acheter les marchandises nécessaires à sa toilette et à son ménage, quelques gâteries pour ses enfants, ou les bijoux bon marché qui constituent son modeste luxe.

La poule marocaine, source de ces revenus, descend, comme ses congénères des autres pays, de gallinacés qui vivent encore à l'état sauvage dans les jungles asiatiques tropicales, aux Indes, en Birmanie, au Siam et dans l'tle de Sumatra.

Le coq sauvage, dit de
Bankhiva, se croise assez fréquemment avec les poules domestiques à la lisiere des forêts du Laos.

Il est bien difficile de décrire les caractères propres de la poule marocaine.

Son plumage, en général plutôt terne, souvent brun ou fauve, varie du blanc au noir en passant par tous les mélanges de teintes grises ou rousses. La crète est d'habitude simple, les oreillons clairs et les barbillons de taille moyenne, mais les poules huppées ne sont pas rares. Presque toujours les yeux sont marrons ou noirs, les membres te le bec noirs.

Légère, haute sur pattes, la tête petite, le cou long, la poitrine étroite, le bassin peu ouvert, elle ne présente aucune précocité.

Le poids de la carcasse ne dépasse guère' $1 \mathrm{~kg} .400$ chez le coq et $1 \mathrm{~kg}$. 200 chez la poule. La chair est de qualité assez médiocre.

Comme tous les animaux domestiques qui peuplent le Maroc, la poule, petite, se distingue avant tout par une remarquable rusticité qui lui permel de vivre de ce qu'elle trouve autour des douars et des tentes, de supporter, malgré sa vivacité naturelle, la vie à l'attache autour d'un piquet, le voyage, la tête en bas pendue par les pattes. Cependant, elle fournit une ponte appréciable, que traduisent les, statistiques de commerce extérieur. Elle est même capable

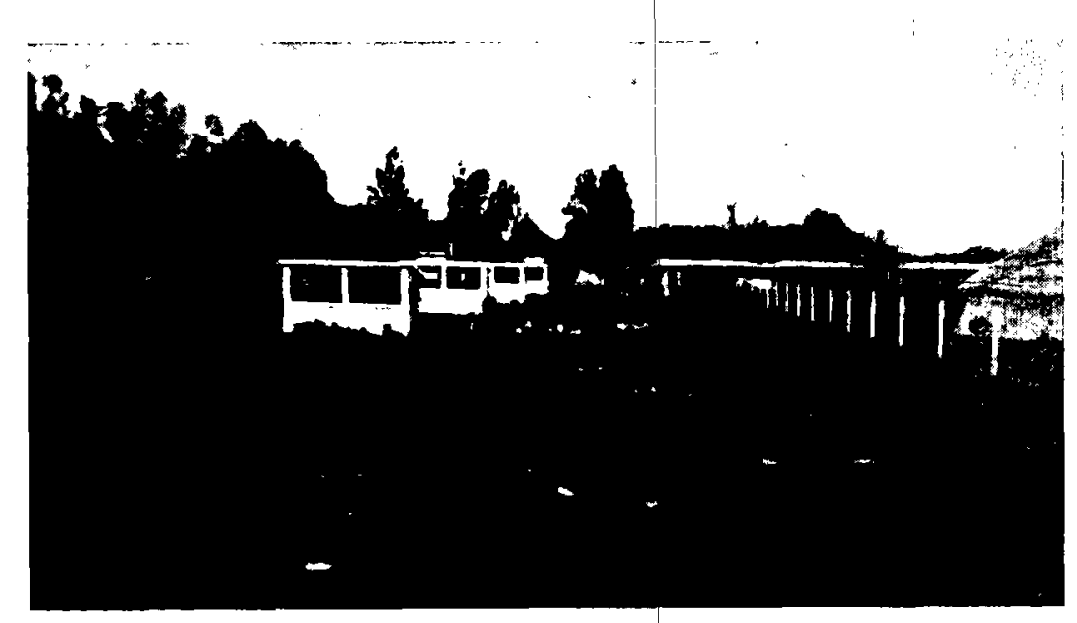

Station avicole du Service de l'Élevage, Meknès. Poulaillers de la ferme 


\begin{tabular}{|c|c|c|c|}
\hline \multicolumn{3}{|c|}{ EXPORTATION D' DUUS EN TONNES $^{-1}$} \\
\hline Années & Eufs exportés & Ánnées & Eufs exportés \\
\hline 1912 & 4.711 & 1931 & 8.520 \\
1913 & 3.125 & 1932 & 8.941 \\
1914 & 952 & 1933 & 9.910 \\
1915 & 2.955 & 1934 & 9.693 \\
1916 & 4.721 & 1935 & 10.430 \\
1917 & 5.215 & 1936 & 10.193 \\
1918 & 5.310 & 1937 & 9.886 \\
1919 & 8.625 & 1938 & 6.227 \\
1920 & 4.233 & 1939 & 6.385 \\
1921 & 5.822 & 1940 & 12.247 \\
1922 & 9.534 & 1941 & 10.208 \\
1923 & 8.674 & 1942 & 4.813 \\
1924 & 10.666 & 1943 & 1.301 \\
1925 & 10.365 & 1944 & 1.170 \\
1926 & 10.057 & 1945 & 271 \\
1927 & 7.622 & 1946 & 13 \\
1928 & 8.349 & 1947 & $3.014(2.666)$ \\
1929 & 12.035 & 1948 & 4.703 \\
1930 & 9.885 & 1949 & 1.262 \\
& & $(8$ mois) & \\
\hline
\end{tabular}

d'engraisser dès qu'on veut bien lui accorder une nourriture convenable.

Le chaponnage, praliqué de ternips à autre par de vieilles femmes, selon des procédés très primitifs, permet d'obtenir des oiseaux bien développés, aux blancs charnus, 'très supérieurs : en viande aux maigres cogs présentés d'habitude sur les marchés.

La poule, excellente couveuse, pond par an une cinquantaine d'œufs d'un blanc terne dont le poids varie entre 45 et 50 grammes, tandis que le poids moyen d'un oeuf de France atteint au moins 55 grammes.

La poule marocaine connaît de nombreux ennemis : les bêtes de proie, les parasites, vecteurs de la spirillose (mal des pattes bien connu de tous les éleveurs de volailles du Maroc) et surtout les diverses maladies contagieuses : choléra, diphtérie et, depuis deux ans, peste, qui ravagent périodiquement les basses-cours et qui sont malheureusement répandues de proche en proche à la faveur du colportage.

L'amélioration d'une production aussi intéressante n'a pas été négligée.

Depuis 1934, l'Office Chérifien de Contrôle et d'Exportation vérifie la qualité et le classement des ceufs exportés, qui ont, de la sorte, une réputation excellente sur les marchés européens.

Le Service de l'Élevage, tout en s'efforçant de lutter contre les diverses maladies des volailles, a tenté, par l'introduction de races perfectionnées, d'obtenir, en même temps que des poulets plus charnus, des œufs plus gros et légèrement teintés, plus

\begin{tabular}{|c|c|c|}
\hline \multicolumn{2}{|c|}{ EXPORTATION DE VOLAILLES EN TONNES :" } \\
\hline Années & Volailles vivantes & Volailles mortes \\
\hline 1933 & 6 & 0,2 \\
1934 & 184 & 3 \\
1935 & 226 & 31 \\
1936 & 153 & 8 \\
1937 & 109 & 33 \\
1938 & 267 & 22 \\
\hline
\end{tabular}

recherchés par les consominateurs de l'extérieur.

En 1930, une Station Avicole Expérimentale a été créée à Meknès. Cet établissement cède chaque année, par l'intermédiaire des Sociétés Indigènes de Prévoyance et des Syndicats d'Élevage, de dix à vingt mille ceufs à couver de races acclimatées dans ses parquets.

Le choix des éleveurs, frappés par la' petite taille des poules marocaines, va de préférence vers les volailles de gros format. La Leghorn, excellente pondeuse, mais en verité de chair médiocre, la Bresse noire, dont la réputation n'est plus à faire en France, n'ont connu aucun succes au Maroc parce, que trop petites. Par contre; la Rhode-I'sland d'une part, la Sussex herminée d'autre part, y sont très appréciées actuellement.

La première est une grande volaille, forte, à beau plumage rouge cuivré rehaussé de plumes noires. Ses cufs bruns atteignent le poids de 60 à 65 grammes. On peut lui reprocher la coloration jaune foncé de sa peau qui donne aux carcasses un aspect particulier.

La Sussex herminée, plus ramassée que la RhodeIsland, est, comme son nom l'indique, blanche avec des plumes noires, régulièrement disposées, en particulier sur le cou et à la queue. Les oeufs sont légèrement teintés. La peau est blanche. C'est une race qui convient également pour la production de la chair et des œufs. Elle se répand de plus en plus en France où ses aptitudes mixtes sont très appréciées.

Cependant, il ne convient pas d'attacher à la race une importance excessive. S'il est vrai qu'il est bons chevaux de tous poils, on peut dire aussi qu'il est de bonnes poules de tous plumages. Le choix doit porter avant tout sur une bonne lignée, dont les qualités de ponte ont été soigneusement sélectionnées et les conditions de santé garanties.

Quelle que soit la race retenue par l'aviculteur. désireux de fonder un poulailler, la réussite dépendra surtout des soins d'hygiène dont il entourera ses volailles, sans négliger la nourriture, car il ne faut pas oublier que la poule, selon la formule chère aux Américains, pond par le bec. 